\title{
Impact of crystallization firing process on the microstructure and flexural strength of zirconia-reinforced lithium silicate glass-ceramics
}

\author{
Hilton Riquieri ${ }^{a}$, Jaiane Bandoli Monteiro ${ }^{a}$, Diogo Cabecinha Viegas ${ }^{b}$, \\ Tiago Moreira Bastos Campos ${ }^{c}$, Renata Marques de Melo ${ }^{a, *}$, \\ Guilherme de Siqueira Ferreira Anzaloni Saavedra ${ }^{a}$ \\ a Department of Dental Materials and Prosthodontics, São Paulo State University (UNESP), Institute of Science and \\ Technology, 777 Eng. Francisco José Longo Avenue, 12245-000, São José dos Campos, SP, Brazil \\ b Faculty of Dental Medicine, Lisbon University, 1649-003, Lisbon, Portugal \\ c Aeronautics Technological Institute (ITA), 50 Praça Marechal Eduardo Gomes, 12228-900, São José dos Campos, \\ São Paulo State, Brazil
}

\section{A R T I C L E I N F O}

Article history:

Received 10 January 2018

Received in revised form

21 May 2018

Accepted 7 June 2018

Keywords:

Dental materials

Dental ceramics

Computer-aided manufacturing

Biaxial flexural strength

\begin{abstract}
A B S T R A C T
Objectives. The aim of this study was to characterize the microstructure of two zirconiareinforced lithium silicate (ZLS) glass-ceramics and evaluate their mechanical properties before and after the crystallization firing process (CFP).

Methods. Field emission-scanning electron microscope (FE-SEM) and energy-dispersive X-ray spectroscopy (EDS) analyses were performed for microstructural characterization. To evaluate the pattern of crystallization and the molecular composition of ZLS glass-ceramics, was used X-ray diffraction (XRD). Vickers hardness, fracture toughness by the indentation method, and biaxial flexural strength were also measured. One hundred and forty ceramic discs were produced (diameter $=12 \mathrm{~mm}$; thickness $=1.2 \mathrm{~mm}$ ) and allocated among four groups $(\mathrm{n}=30)$ : Sfir, Sunf-ZLS Vita Suprinity; and Cfir and Cunf-ZLS Celtra Duo; fired and unfired, respectively. Statistical analysis was performed and Weibull failure probabilities were calculated.

Results. Cfir showed the highest characteristic strength $(251.25 \mathrm{MPa})$ and hardness $(693.333 \pm 10.85 \mathrm{GPa})$. Conversely, Sunf presented the lowest characteristic strength $(106.95 \mathrm{MPa})$ and significantly lowest hardness $(597.533 \pm 33.97 \mathrm{GPa})$. According to Weibull analysis, Sunf had the highest structural reliability $(\mathrm{m}=7.07)$, while Sfir presented the lowest $(m=5.38)$. The CFP was necessary to crystallize zirconia in the partially crystallized ZLS glass-ceramics. Sfir had a lower percentage of crystallized zirconia than did Cfir. Fractographic analyses showed that all failures initiated from an inherent critical defect in Sunf and from processing defects in the remaining groups.
\end{abstract}

\footnotetext{
* Corresponding author at: São Paulo State University (UNESP), Institute of Science and Technology, Francisco José Longo, 777, Jardim São Dimas, São José dos Campos, São Paulo, Brazil.

E-mail addresses: hilton.riquieri@terra.com.br (H. Riquieri), jaiane.monteiro@ict.unesp.br (J.B. Monteiro), diogo.pviegas@gmail.com (D.C. Viegas), moreiratiago22@gmail.com (T.M.B. Campos), renata.marinho@fosjc.unesp.br, marquesdemelo@gmail.com (R.M. de Melo), saavedra@ict.unesp.br (G. de Siqueira Ferreira Anzaloni Saavedra).

https://doi.org/10.1016/j.dental.2018.06.010

0109-5641/@ 2018 The Academy of Dental Materials. Published by Elsevier Inc. All rights reserved.
} 
Significance. The CFP had a direct influence on the flexural strength and microstructural characteristics of both ZLS materials.

(C) 2018 The Academy of Dental Materials. Published by Elsevier Inc. All rights reserved.

\section{Introduction}

The constant search for all-ceramic restorative materials that combine aesthetics and strength has contributed to the development of reinforced glass-ceramics [i.e., zirconia-reinforced lithium silicate (ZLS) glass-ceramics] by the companies Vita and Dentsply, in conjunction with the Fraunhofer Institute for Silicate Research (Germany), and marketed separately as different products, i.e., Vita Suprinity (Vita) and Celtra Duo (Dentsply) [1,2]. Both ZLS glass-ceramics are indicated for inlays, onlays, full-contour anterior and posterior crowns, and also for implant-supported prostheses $[3,4]$.

The glassy matrix of vitreous ceramics is highly susceptible to crack propagation [5] and to degradation under fatigue loads [1]. Glass-ceramics such as those studied here have been developed to overcome those deficiencies and create even higher-performance ceramic materials [1]. The manufacturers claim that the zirconia dioxide content incorporated into ZLS glass-ceramics is ten times higher than that in other glassceramics [6,7]. This component is arranged in small grains and could result in higher resistance and better superficial polishing [8]. Previous studies, however, have called attention to the low efficacy of zirconia for stopping crack propagation [9], as this is simply a form of commercial appeal [1]. Moreover, ZLS materials continue to belong to a class of sensitive acid ceramics, meaning that their surface can be etched by hydrofluoric acid [10].

ZLS glass-ceramics are marketed in a pre-processed state, available as pre-fabricated ceramic blocks, which allows for fewer internal flaws and a high-quality and reliable ceramic restoration produced in a mechanized/subtractive way [3]. To make the milling process easier, ZLS glass-ceramics are available in a meta-sintered (intermediate) stage and only after undergoing a CFP in which the lithium silicate crystals will grow and the ceramic gains its final color and strength $[1,11]$. Recently, the simplification of the clinical steps pushed manufacturers to produce blocks in fully crystallized state that can be milled and cemented, although Dentsply reports lower flexural strengths for "mill and polish only" specimens, which led us to the belief that full crystallization is one step further. Thus, the differences in crystalline phases in vitreous ceramics - mainly the effects on mechanical properties and toughening mechanisms depending on the crystallization state - remain to be determined.

The aim of the present study was to evaluate the microstructure of ZLS glass-ceramics in partially or fully crystallized states, as well as to evaluate the mechanical properties of these ceramics before and after the crystallization process. To evaluate the ceramics, we performed crystallization firing schedules and not only the stain/glaze firing recommended by Celtra Duo manufacturer (Dentsply). The null hypothesis tested was that the ZLS glass-ceramics would have the
Table 1 - Crystallization chart firing of Vita Suprinity and Celtra Duo.

Vita Suprinity Celtra Duo

\begin{tabular}{lll}
\hline Initial chamber temperature $\left({ }^{\circ} \mathrm{C}\right)$ & 400 & 400 \\
Time at the initial temperature $(\mathrm{min})$ & 8 & 8 \\
Temperature rate increase $\left({ }^{\circ} \mathrm{C} / \mathrm{min}\right)$ & 55 & 55 \\
Crystallization temperature $\left({ }^{\circ} \mathrm{C}\right)$ & 840 & 830 \\
Holding time $(\mathrm{min})$ & 8 & 10 \\
Ending temperature $\left({ }^{\circ} \mathrm{C}\right)$ & 680 & 700 \\
\hline
\end{tabular}

same mechanical properties and microstructural characteristics before and after the crystallization firing.

\section{Materials and methods}

Zirconia-lithium silicate glass-ceramic materials (Vita Suprinity - Vita Zahnfabrik, H. Rauter GmbH \& Co., Bad Säckingen, Germany, batch number 49270; and Celtra Duo - Degudent $\mathrm{GmbH}$, Hanau, Wolfgang, Germany, batch number 18018171) were used to produce 140 ceramic discs. The specimens were further divided into two test conditions, with or without crystallization firing.

\subsection{Specimen preparation}

The ceramic blocks were machined in a conventional lathe (Nardini, Americana, São Paulo, Brazil) to obtain cylinders ( $\sim 12 \mathrm{~mm}$ in diameter) that were cut into discs in a precision cutting machine (Isomet 1000, Buehler, Lake Bluff, IL, USA), with the final thickness of $1.2 \mathrm{~mm}$.

The ceramic specimens were randomly separated, and half the discs of both materials were subjected to a crystallization cycle in a specific oven for each ZLS glass-ceramic (Vita Vacumat 6000MP, Vita Zahnfabrik; Multimat, Dentsply/Sirona (Table 1). 'The crystallization firing of Vita Suprinity followed the manufacturer's recommendations while that of Celtra Duo was based on the materials' appearance and personal conversations with a technician and Dentsply consultant. For this process, the specimens were positioned inside the oven on top of a porous refractory material, allowing for homogeneous heat distribution. A metallic device with a central cavity and the desired dimensions (diameter $=12 \mathrm{~mm}$; thickness $=1.2 \mathrm{~mm}$ ) (Fig. 1) was used to allow the specimens to be better polished in the polishing machine (Ecomet 250 Grinder Polisher, Buehler), with silicon carbide papers of \#400-, \#600-, \#1200-, and \#2500-grit (Buehler). The specimens final dimensions were according to ISO $6872: 2008$ [12], that is, $12 \mathrm{~mm}$ in diameter and $1.2 \mathrm{~mm}$ thick. A mirror-like polishing was performed (Fig. 2).

All samples were manually polished with felt wool discs (Kota, São Paulo, Brazil) at $5000 \mathrm{rpm}$, under refrigeration by the same abrasive liquid solution with a diamond powder in 


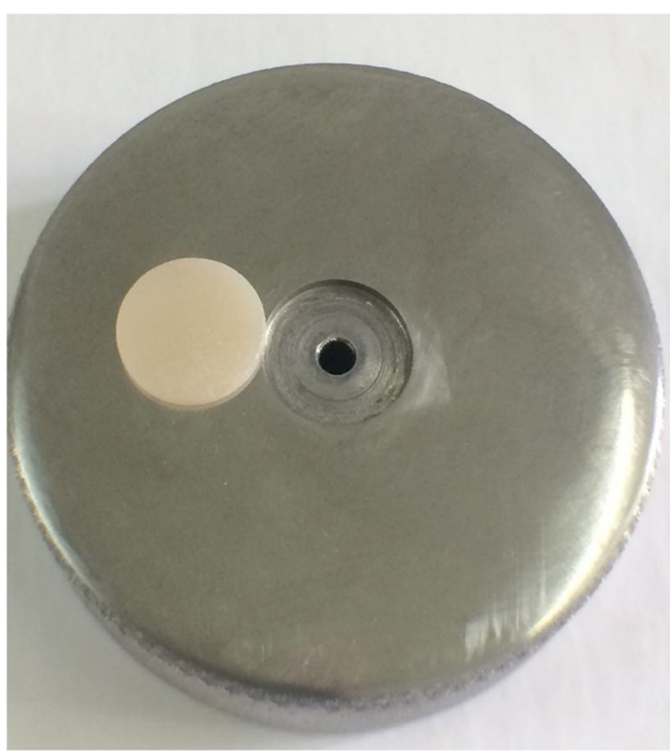

Fig. 1 - Stainless steel metal device built up with a central cavity with dimensions of $12 \mathrm{~mm}$ in diameter and $1.2 \mathrm{~mm}$ in thickness for polishing the ceramic discs for polishing the ceramic discs and specimen after being polished.

suspension (grit of $15 \mu \mathrm{m}$ and $0.6 \mu \mathrm{m}$; Extec Corp, Enfield, CT, USA) for $30 \mathrm{~s}$ each, until the disc surfaces were shining and without scratches. Twenty samples were randomly allocated for complementary analysis.

\subsection{Biaxial flexural strength tests and Weibull analysis}

For the determination of flexural strength, the samples $(n=120)$ were subjected to a biaxial flexure strength test according to ISO 6872:2008 [12]. The disc-shaped specimens were positioned on three support balls (diameter $=3.2 \mathrm{~mm}$ ), which were placed $10 \mathrm{~mm}$ equidistant from each other in a triangular position. The tests were performed in ambient air, and a flat circular piston (diameter $=1.6 \mathrm{~mm}$ ) attached to a load cell of $1000 \mathrm{kgf}$ in a universal testing machine (Emic DL-1000, Emic, São José dos Pinhais, Paraná, Brazil) applied the load $(1 \mathrm{~mm} / \mathrm{min})$ in the center of the sample until catastrophic fail- ure occurred. A piece of adhesive tape (3M ESPE, Minneapolis, MN, USA) was placed on the compressive side of each sample to provide better contact distribution between the piston and the ceramic discs, and to avoid spreading the fragments [13]. The biaxial flexure strength $(\sigma)(\mathrm{MPa})$ calculations were based on the following equation:

$\sigma=-0.2387 \mathrm{P} \frac{(\mathrm{X}-\mathrm{Y})}{\mathrm{b}^{2}}$

where $\mathrm{P}$ is the load in $\mathrm{N}, \mathrm{X}$ and $\mathrm{Y}$ are the parameters related to elastic properties of the material (for Celtra Duo and Vita Suprinity, Poisson's ratio $=0.222$ and 0.208; Young's modulus $=107.9$ and 104.9, respectively, as previously given by Wendler et al.) [2], and $b$ is the specimen thickness at the fracture origin, in $\mathrm{mm}$.

The data obtained in the flexural strength test were recorded and subjected to Weibull analysis. The characteristic strength $\left(\sigma_{0}\right)$ is the value corresponding to the approximately $62.3 \%$ failure probability, and the Weibull modulus (m) expresses the reliability of the ceramic material, being a higher value than a close grouping of the flexural stress data. Weibull analysis was performed according to the two-parametric distribution described by Quinn and Quinn [14], in the following equations:

$\mathrm{P}_{f}=1-\exp -\frac{(\sigma)^{\mathrm{m}}}{\sigma_{\mathrm{m}}}$

$\ln \left(1-\mathrm{P}_{f}\right)=\left(-\frac{\sigma}{\sigma_{\mathrm{m}}}\right)^{\mathrm{m}}$

$\ln \left[\ln \left(\frac{1}{1-\mathrm{P}_{f}}\right)\right]=\operatorname{nln} \sigma-\operatorname{mln} \sigma_{\theta}$

The statistical differences among the characteristic strength data were determined by the absence of overlap of the $95 \%$ confidence intervals.

\subsection{Vickers hardness and fracture strength toughness} $\left(\mathrm{K}_{\mathrm{Ic}}\right)$ by the indentation method

Three discs of both ZLS materials were dedicated to face indentation in a Vickers microhardness tester (Shimadzu
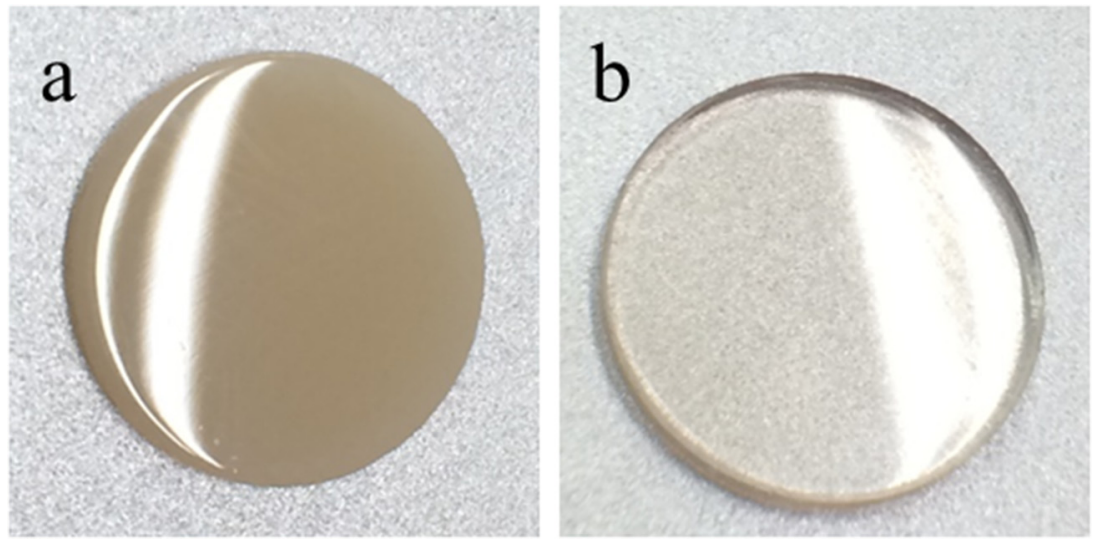

Fig. 2 - Specimen of Cunf and Sfir after being polished. 

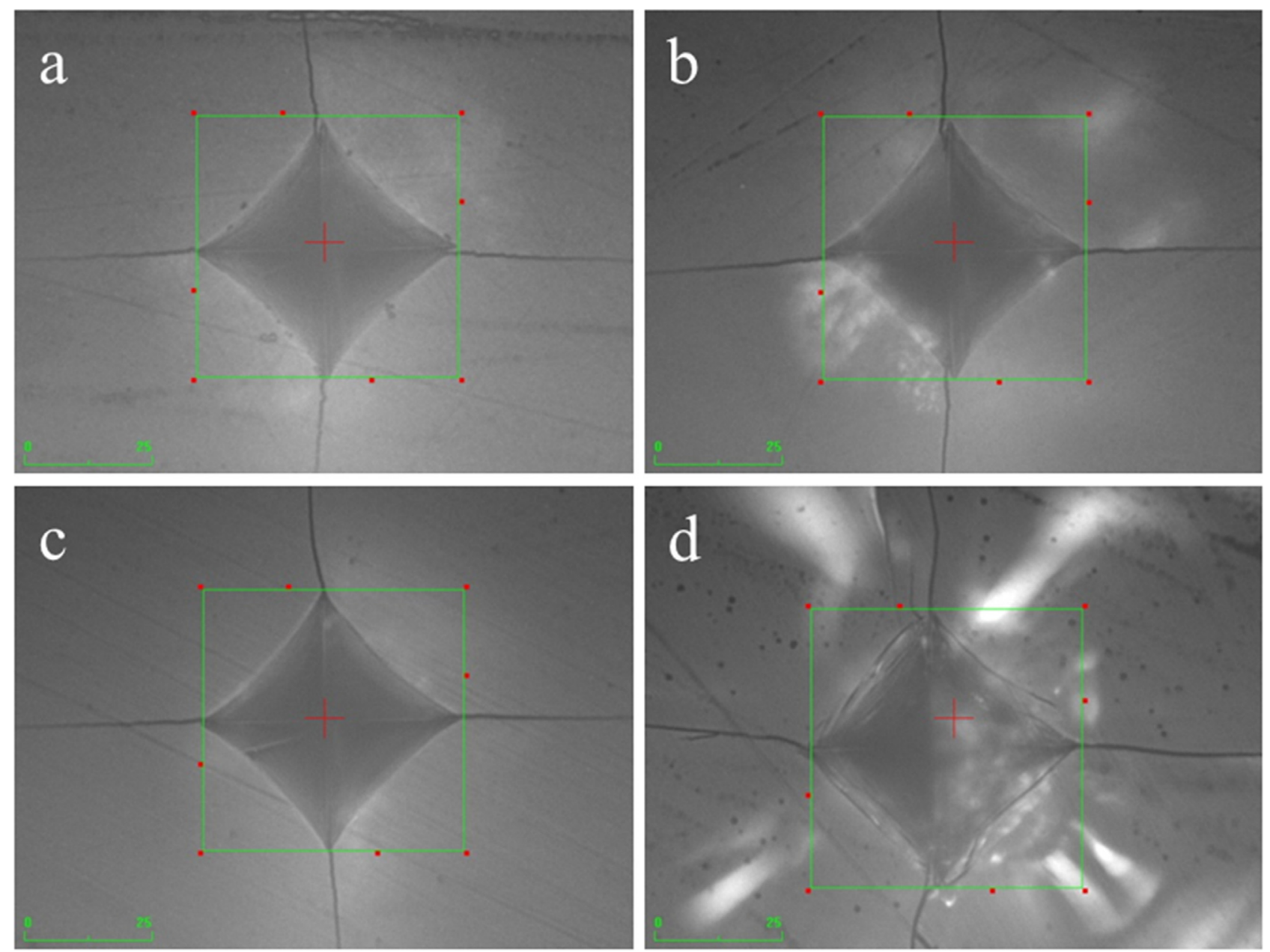

Fig. 3 - Representative images of Vickers indentations for all the tested conditions: (a) Cfir, (b) Cunf, (c) Sfir, and (d) Sunf.

Micro Hardness tester, HMV-G 21DT model, Shimadzu, Kyoto, Japan) with a load of $0.1 \mathrm{~N}$ for $10 \mathrm{~s}$, which produced an acceptable crack pattern, following the ASTM C 1327-03 recommendations [15] (Fig. 3). Five indentations (10x magnification) were made in each sample, with a distance of at least $0.5 \mathrm{~mm}$ from each other. The indentation area was automatically calculated by software (HMV-G Series Test Software, Shimadzu Corporation, Japan), from microscopic measurements of the diagonals of the impressions [16]. Vickers hardness was obtained by the equation $\mathrm{VH}=1.854 \mathrm{~F} / \mathrm{d}^{2}$, where VH is the Vickers hardness, $\mathrm{F}$ is the load in kgf, and $\mathrm{d}$ is the arithmetic average between two diagonals in $\mathrm{mm}$ (indentation area). After averaging the indentations made on each sample, the mean hardness and standard deviations were obtained for each material $(n=3)$ and submitted to One-way ANOVA and Tukey's test $(\mathrm{p}<0.05)$.

Mean crack length was obtained by the indentation method immediately after the hardness tests. Fracture toughness values were then determined automatically by the indenter equipment, based on the ASTM Standard C1327 [15]. The fracture toughness $\left(K_{\text {IC }}\right)$ of the samples (in MPa. ${ }^{1 / 2}$ ) was estimated by measurement of the cracks made by the indentation according to ISO 15732:2003 [17] and JIS R 1607:2010 [18,19], by the following equation: $K_{\text {IC }}=0.026 \mathrm{E}^{1 / 2} \mathrm{P}^{1 / 2} \mathrm{a} / \mathrm{C}^{3 / 2}$, where $K_{\text {Ic }}$ is the fracture toughness in MPa $\mathrm{m}^{1 / 2}, \mathrm{E}$ is the Young's modulus in $\mathrm{Pa}, \mathrm{P}$ is the load in $\mathrm{N}, \mathrm{C}$ is $1 / 2$ of the mean length of the crack in $\mu \mathrm{m}$, and $\mathrm{a}$ is $1 / 2$ of the mean length between the diagonal lines of the indentation in $\mu \mathrm{m}$.

The values of fracture toughness $\left(K_{\text {Ic }}\right)(n=3)$ obtained (mean and standard deviation) and the mean crack lengths are presented in Table 2. Data were analyzed by One-way ANOVA and Tukey's test $(\mathrm{p}<0.05)$.

\subsection{Field emission-scanning electron microscope (FE-SEM), energy-dispersive $\mathrm{X}$-ray spectroscopy (EDS), and $\mathrm{X}$-ray diffraction (XRD)}

The FE-SEM analyses were performed in samples with polished surfaces that received $10 \%$ hydrofluoric acid-etching (Dentsply, Brazil) for $20 \mathrm{~s}$. The specimens were examined by means of a high-resolution field emission gun-scanning electron microscope (SEM) (Magellan 400L, FEI Company, Brno, Czech Republic) with a secondary electron (SE) and a back-scattered scanning electron (BSE) detector allowing for observation of the sizes and shapes of the grains under magnifications of $10,000 \times, 40,000 \times$, and 100,000x. 
Table 2 - Weibull modulus $(\mathrm{m})$, confidence interval of Weibull modulus (CI), characteristic strength $\left(\sigma_{0}\right)$ of the materials, with minimum-maximum values $(\mathrm{MPa})$, Vickers hardness $(\mathrm{GPa})$, fracture toughness $\left(\mathrm{K}_{\mathrm{Ic}}\right)$, and average crack length $(\mu \mathrm{m})$.

\begin{tabular}{|c|c|c|c|c|}
\hline & Sunf & Sfir & Cunf & Cfir \\
\hline $\mathrm{m}$ & 7.07 & 5.38 & 5.86 & 5.77 \\
\hline CI (lower-upper) & $6.24-8.00$ & $4.01-7.23$ & $5.10-6.74$ & $4.29-7.76$ \\
\hline$\sigma_{0}(\mathrm{MPa})$ & 106.95 & 191.02 & 163.86 & 251.25 \\
\hline$\sigma_{0}$ mininum $-\sigma_{0}$ maximum & $100.94-113.33$ & 178.10-204.89 & $153.21-175.26$ & $235.36-268.21$ \\
\hline Vickers hardness (GPa) & $597.533 \pm 33.97^{B}$ & $683.267 \pm 16.07^{\mathrm{A}}$ & $682.400 \pm 15.31^{\mathrm{A}}$ & $693.333 \pm 10.85^{\mathrm{A}}$ \\
\hline $\mathrm{K}_{\mathrm{Ic}}\left(\mathrm{MPa} \mathrm{m}^{1 / 2}\right)$ & $2.21 \pm 0.11^{a}$ & $2.63 \pm 0.14^{a}$ & $2.26 \pm 0.80^{a}$ & $2.51 \pm 0.59^{a}$ \\
\hline Average crack length ( $\mu \mathrm{m})$ & $55.77 \pm 1.59$ & $52.10 \pm 0.61$ & $52.14 \pm 0.58$ & $51.72 \pm 0.40$ \\
\hline
\end{tabular}

Note: Different capital and lower case letters mean statistically significant differences for Vicker's hardness and fracture toughness means, respectively.

The chemical composition of the microcompounds was obtained by energy-dispersive X-ray spectroscopy (EDS) (Bruker Nano GmbH 410, Berlin, Germany).

An X-ray diffractometer (XRD) (X'pert Powder, PANalytical, Almelo, Netherlands) was used to identify the crystalline content in one specimen per group, by software with an X'Pert HighScore database (PANalytical).

\subsection{Fractographic analysis}

The fractured surfaces were analyzed by stereomicroscopy in all tested samples (Discovery V20, Carl Zeiss, Göttingen, Germany). One representative specimen from each group was examined under SEM (Inspect S50, FEI Company, Brno, Czech Republic) at $200 \times$ and $1000 \times$ magnifications.

\section{Results}

\subsection{Biaxial flexure strength tests and Weibull} parameters

The ceramics' properties, measured at different stages of crystallization, and the Weibull parameters are described in Table 2.

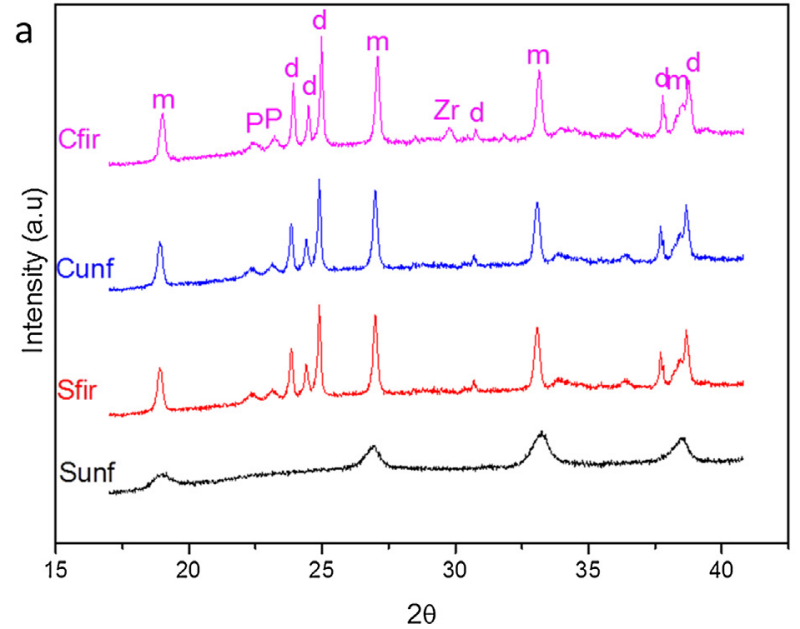

The CFP influenced the flexural strength, and the crystallized samples presented higher characteristic strength values. In spite of that, the Weibull modulus of all groups were statistically similar due to the overlap of confidence intervals. The Sunf ceramic tended to present a higher Weibull modulus, indicating that the defects inherently present in the blocks were similar in size and were homogeneously distributed.

\subsection{Vickers hardness and fracture strength toughness $\left(\mathrm{K}_{\mathrm{Ic}}\right)$ by the indentation method}

Cfir, Cunf, and Sfir presented statistically similar Vickers hardnesses, whereas that of Sunf was statistically lower. The fracture toughness measured by the indentation method was the same for all groups (Table 2).

\subsection{Microstructure characterization}

The damage analyses made by the Vickers indentation are presented individually and are described in Table 2. The images are displayed in Fig. 3.

XRD analyses (Fig. 4) of Sunf showed large peaks corresponding to nanocrystalline lithium metasilicate. The diffractograms of Cfir, Cunf, and Sfir showed lithium metasilicate $\left(\mathrm{Li}_{2} \mathrm{SiO}_{3}\right)$, lithium disilicate $\left(\mathrm{Li}_{2} \mathrm{Si}_{2} \mathrm{O}_{3}\right)$, and phosphorus. Cfir presented a small tetragonal zirconia peak, which was not

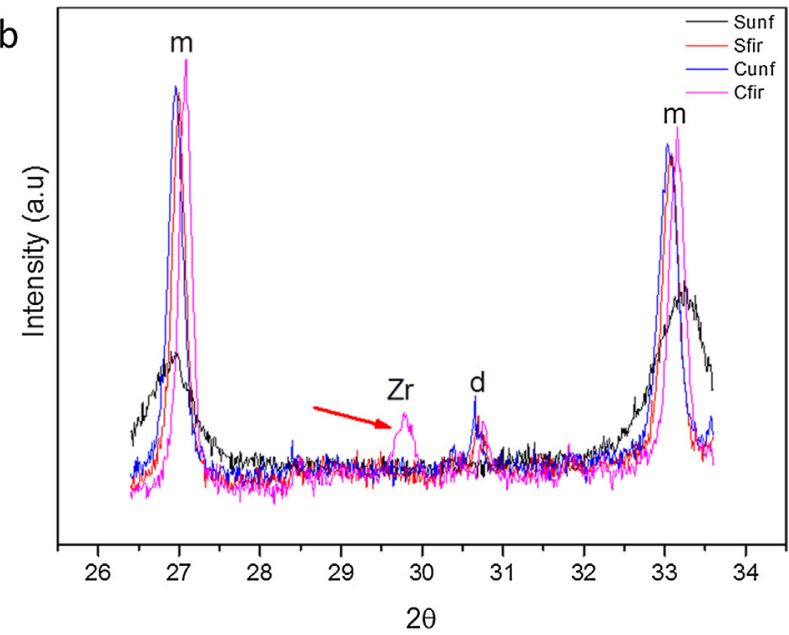

Fig. 4 - Difractograms (a and b) of Sunf, Sfir, Cunf, and Cfir, being $\mathbf{m}=$ lithium metasilicate, $d$ = lithium disilicate, $\mathrm{P}=$ phosphorus, $\mathrm{Zr}$ = tetragonal zirconia. The only prominent $\mathrm{Zr}$ peak appears in Cfir, which is even more evident with overlapping of the graphs (b). 


\begin{tabular}{lcc}
$\begin{array}{l}\text { Table } 3 \text { - Mass content (in percentage) of ZLS } \\
\text { glass-ceramics by EDS analysis. }\end{array}$ \\
\hline Ceramic Material & Sfir & Cfir \\
\hline Oxygen & 52.60 & 53.09 \\
Silicious & 30.95 & 30.85 \\
Zirconium & 13.00 & 12.50 \\
Potassium & 2.06 & 2.36 \\
Aluminium & 1.35 & 1.17 \\
\hline
\end{tabular}

present on the material before crystallization (Cunf), showing that the CFP changed the zirconia crystallinity. Sfir did not present a high and clear peak of tetragonal zirconia, indicating a lower content of that material.

Table 3 shows the chemical constituents of the studied materials after the CFP. Cfir and Sfir presented similar percentages of atomic mass; however, as expected, lithium, one of the main elements of both materials, could not be estimated by EDS due to its low molecular weight.

The micrographs in FE-SEM, corresponding to secondary electron (SE) and back-scattered electrons (BSE), are presented in Fig. 5. On Cunf, the zirconia grains measure approximately $200 \mathrm{~nm}$ and are present in the glassy matrix, which are monodispersed and larger than in the previous material (diameter between 1.0 and $1.5 \mu \mathrm{m}$ in a higher percentage of glassy matrix). On BSE images, it is possible to observe more clearly the formation of circles, which correspond to round defects or the absence of the glass phase in some portions of the material, similar to bubbles (Fig. 6). Sunf presented a continuous matrix with small grains dispersed in the glassy matrix and cracks uniformly distributed, in addition to zirconia grains of the same diameter as those in Cunf $(\sim 250 \mathrm{~nm})$. In the images of Cfir, it is possible to observe monodispersed round grains, with size between $500 \mathrm{~nm}$ and $1 \mu \mathrm{m}$, and a lower quantity of the glassy phase, as previously described by Belli et al. [1]. It is also possible to identify white spots with a diameter of $\sim 25 \mathrm{~nm}$ that can correspond to zirconia grains. Sfir presents a bimodal distribution, with some grains of about $500 \mathrm{~nm}$ and $2 \mu \mathrm{m}$, embedded in a glassy matrix present in a quantity higher than that in Cfir. As in Cfir, the white spots are indicative of zirconia grains, albeit in a lower quantity.

Fig. 7 shows SEM micrographs of the fractured surfaces of all materials at different magnifications (from $\times 100$ to $\times 1000$ ), and the main fractographic marks are displayed. In the region of the critical defect, it is possible to observe zipper cracks (zc) on Sfir, Cunf, and Cfir samples as a result of high-pressure polishing, while the origins on Sunf are mainly from structural defects.

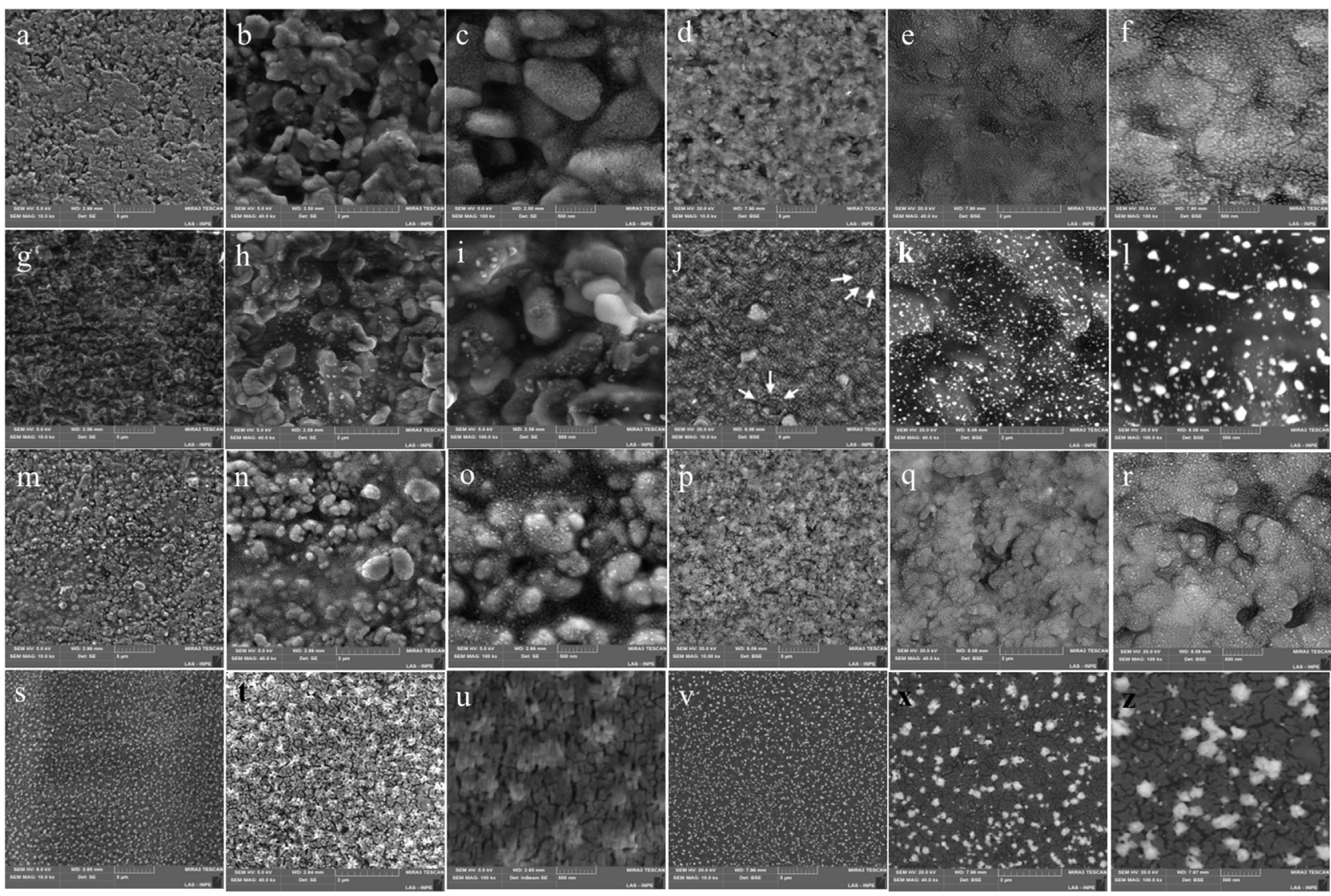

Fig. 5 - Secondary and back-scattered electron micrographs of the tested materials after $10 \%$ hydrofluoric acid-etching for 20 s. Cfir (a-f), Cunf (g-l), Sfir (m-r), and Sunf (s-y). The opaque white spot corresponds to the zirconia phase, whose size changed noticeably after crystallization firing of both materials. There was a post-firing increase in the crystal size in Sunf, whereas there were no major changes in the crystals from Cunf to Cfir. Round marks suggestive of a transient liquid phase are present in Cunf (arrows). Also, the cracked appearance of the glass matrix in Sunf disappears after crystallization firing. 


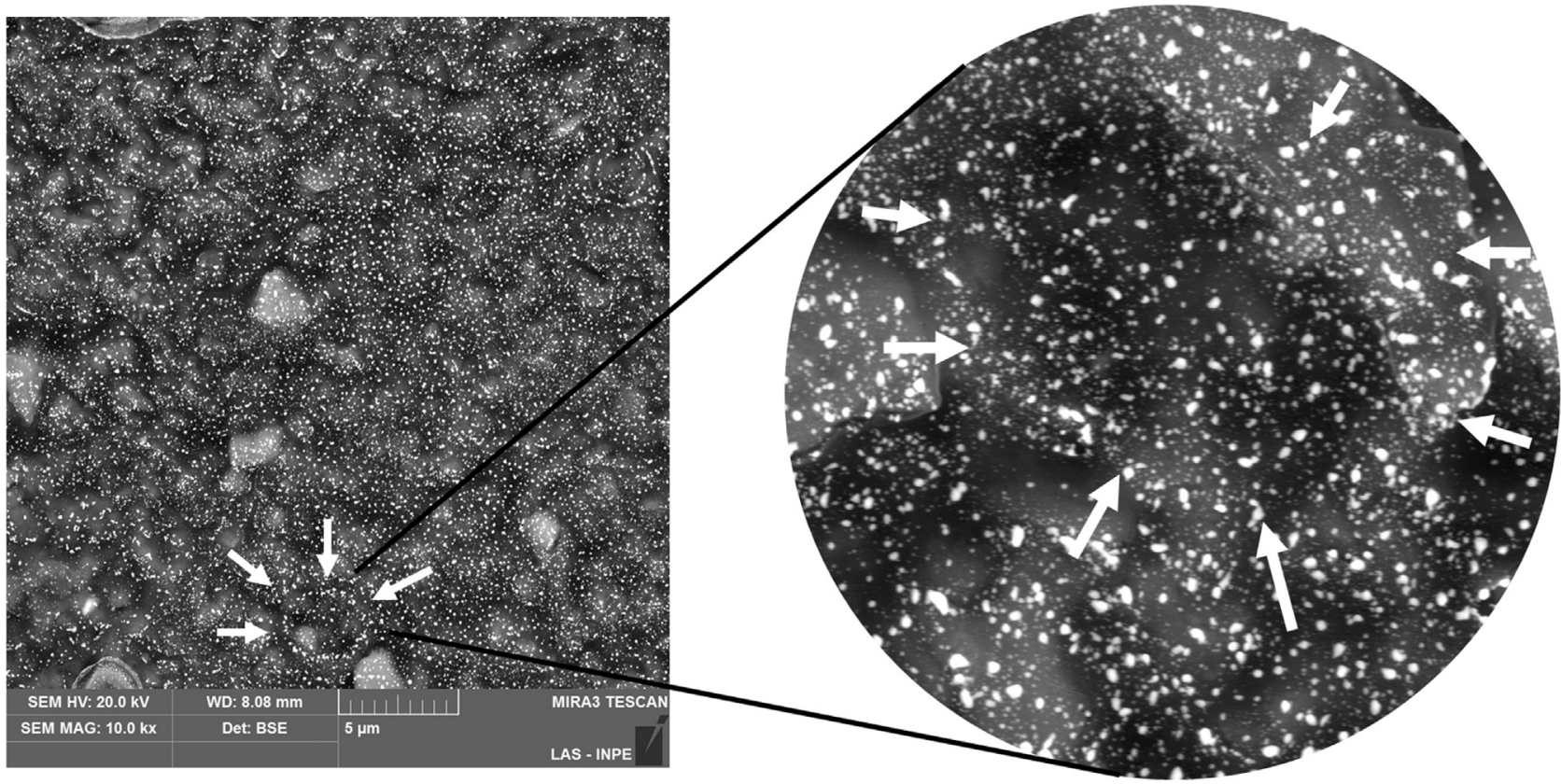

Fig. 6 - FE-SEM images of the microstructure of Cunf (back-scattered electron micrographs). Round marks suggestive of a transient liquid phase are present in Cunf (arrows).

\section{Discussion}

The present study evaluated the mechanical and microstructural properties of zirconia-reinforced lithium silicate glassceramics, before and after the CFP. It can be noted that fully crystallized materials presented lower Weibull modulus than did those partially crystallized. These results demonstrate that the CFP results in a material of very fine microstructure and resistant to polishing, giving rise to new (artificial) defects during sample preparation. SEM evaluation showed that superficial ceramic defects (e.g., zipper cracks) were produced during the polishing process (Fig. 7). Since the polishing of the fully crystallized ceramic samples was performed manually, it imposed more compressive forces-and more residual compressive stresses on the surface- leading to the creation of defects more significant in size than the microstructural flaws of the samples subjected to a CFP [2]. For Sunf, the higher Weibull modulus was due to the inherent defects of the material, as a result of the manufacturing process (uniaxial pressing) of CAD/CAM blocks.

The results of this study showed that Cfir and Sfir presented the highest values of characteristic strength $\left(\sigma_{0}\right)$, fracture toughness $\left(K_{\mathrm{IC}}\right)$, and Vickers hardness $(\mathrm{GPa})$ when compared with Sunf and Cunf (Table 2). Indeed, the CFP had a positive impact - healing of natural flaws, zirconia crystallization (only for Cfir) - on mechanical properties of the tested ceramics, and, in this sense, the null hypothesis that fully crystallized and partially crystallized ZLS have the same mechanical properties was not accepted. The difference found among the values of the tested properties can be a result of their different microstructures [2]. The FE-SEM micrographs of the partially crystallized ceramics after hydrofluoric acid-etching showed round defects similar to bubbles inside the glassy matrix for
Cunf (Fig. 6), and multiple cracks distributed in the entire matrix surface for Sunf. It can be noted that, after the CFP, those characteristics are not visible for Cfir, and a "healing" of the cracks occurred for Sfir (Fig. 5m-y). Due to a significant change in the microstructure, probably due to the vitreous component flowing during heating, the CFP healed any defects created during the fabrication process [20], with the consequent improvement of mechanical properties. The presence of bubbles in Cunf also attests to the existence of glass viscosity during the obtention of the partially crystallized phase (Fig. 5g-1).

From EDS analysis, the crystallized forms presented similar chemical components, mainly oxygen, silicon, zirconia, and lower percentages of potassium and aluminum, in agreement with the findings reported in the literature [9]. The same vitreous and crystalline phases have been confirmed by EDS analysis for both materials after crystallization (Table 3). However, the percentage in mass of zirconia could be overestimated (this study found 12-13\%, in contrast to the manufacturer's claim of $\sim 10 \%$ ), because Belli et al. [1] highlighted the presence of phosphorus, whose peak in EDS is overlapped by the zirconia peak. The results of X-ray diffraction (Fig. 4) showed that these components are present in all tested samples, in the majority of which as nanocrystalline lithium metasilicate peaks $\left(\mathrm{Li}_{2} \mathrm{SiO}_{3}\right)$, which are more intense after the CFP, showing a surrounding vitreous phase and with a more regular distribution of the crystals (Fig. 5).

A previous study with Raman spectroscopy and X-ray diffraction showed that although the same glassy and crystalline phases were present in both materials, the vitreous phase of Celtra Duo presented larger $\mathrm{Li}_{2} \mathrm{SiO}_{3}$ crystallites $(\sim 1 \mu \mathrm{m})$ than did Vita Suprinity $(\sim 0.5 \mu \mathrm{m})$ [2]. The same tendency was observed in the present study. Nevertheless, after crystallization, it was possible to observe the presence of a 


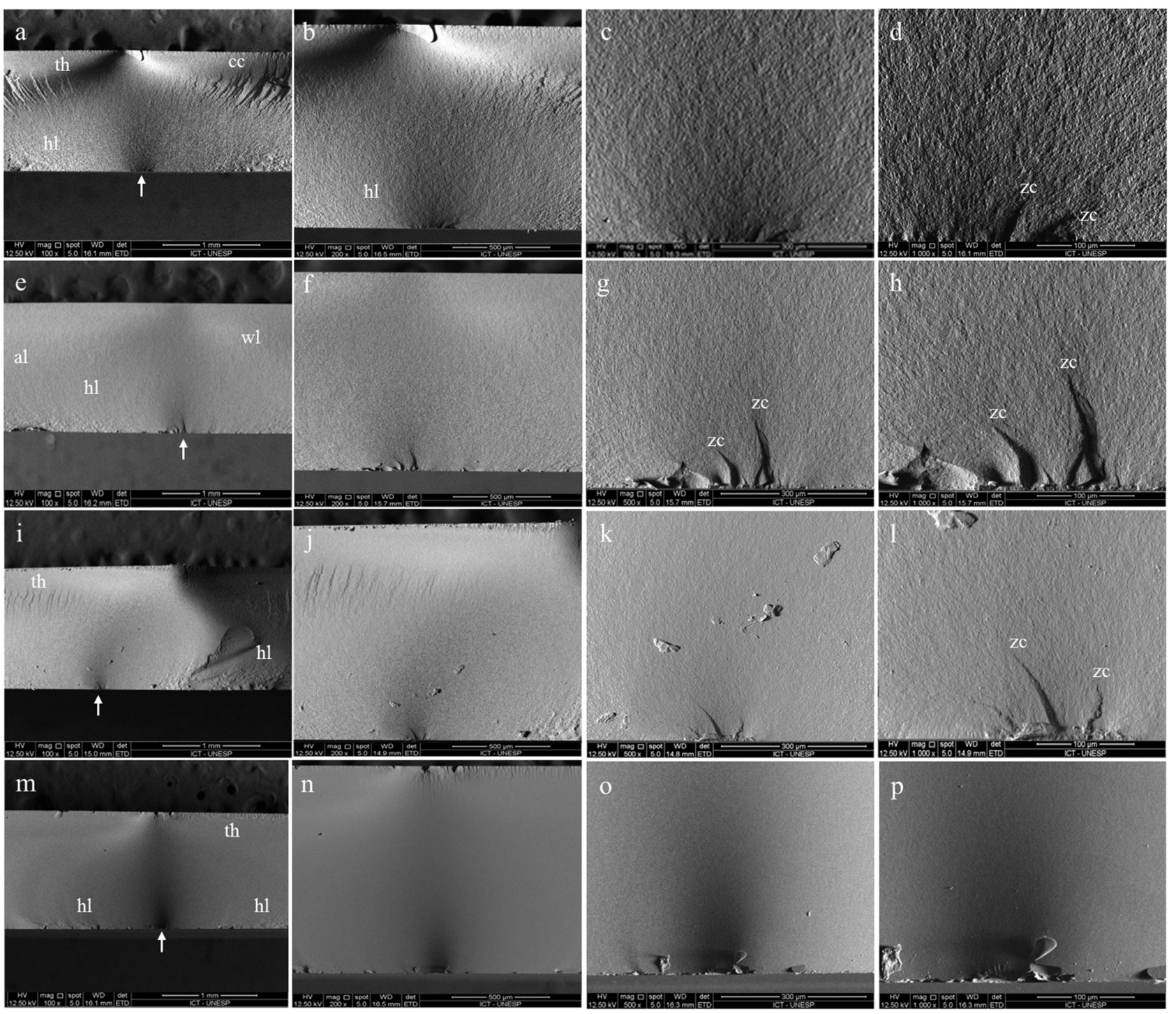

Fig. 7 - SEM images of fractured specimens ( $\times 100, \times 200, \times 500$, and $\times 1000$ magnification). Cfir (a-d), Cunf (e-h), Sfir (i-l), and Sunf $(m-p)$. The white arrows indicate structural flaws on the tensile surface where failure initiated (critical defect). The fracture marks identified are: zc (zipper cracks), hl (hackles), th (twist hackles), cc (compression curl), al (arrest line), and wl (warner lines). The zipper cracks appear as the main fracture mark in the region of the critical defect of Cfir, Cunf, and Sfir.

zirconia peak only for Cfir. According to Krüger et al. [21] and Aurélio et al. [22], the absence of crystalline zirconia after the CFP indicates that $\mathrm{ZrO}_{2}$ remains amorphous and aggregated to the glassy matrix. It appears that zirconia grains decreased after the crystallization process, which may have contributed to higher fracture strength of the crystallized Celtra Duo, as already described in the literature [4,23]. In summary, the many differences in the microstructure of these materials before and after crystallization firing lead to rejection of the anticipated null hypothesis.

In this study, fracture toughness $\left(K_{\text {Ic }}\right)$ was calculated by the Vickers indentation method. The main limitation of this test is certain inaccuracy in exponents and numerical coefficients for calculation of fracture toughness, although it continues to be the most practical method of toughness measurement [24]. The observation of the Vickers indentations showed that Cfir, Cunf, and Sfir exhibited classic Palmquist cracks, where all the radial cracks began at the lateral edge of the pyramid, with slits visible along the midline of the pyramid recess, as described by Fett et al. [25] (Fig. 3). In a closer look at Fig. 3d, it can be noted that Sunf presents a porous glassy matrix that led to the failures of the material, as well as greater crack length, ramifications, and a collapse of the internal indentations, indicating that this material presents a lower fracture resistance than the others.

\section{Conclusion}

To conclude, we found an important change in the microstructure from partially to fully crystallized lithium silicates, mainly, the growth of lithium silicate grains. Zirconia was dispersed in the glass phase and suffered a decrease in size after crystallization. Fully crystallized materials also pre- 
sented higher hardness and flexural strength, but similar Weibull modulus. The fine and harder microstructure created after firing led to a difficulty in polishing, which gave rise to failures due to manual polishing, but the origins in the glassy non-fired lithium silicate (Sunf) were mainly round structural defects.

\section{R E F E R E N C E S}

[1] Belli R, Wendler M, Ligny D, Cicconi MR, Petschelt A, et al. Chairside CAD/CAM materials. Part 1: measurement of elastic constants and microstructural characterization. Dent Mater 2017;33(1):84-98.

[2] Wendler M, Belli R, Petschelt A, Mevec D, Harrer W, Lube T, et al. Chairside CAD/CAM materials. Part 2: flexural strength testing. Dent Mater 2017;33(1):99-109.

[3] Rinke S, Rödiger M, Ziebolz D, Schmidt AK. Fabrication of zirconia-reinforced lithium silicate ceramic restorations using a complete digital workflow. Case Rep Dent 2015;2015, http://dx.doi.org/10.1155/2015/162178. Article ID 162178, 7 pages.

[4] Elsaka SE, Elnaghy AM. Mechanical properties of zirconia reinforced lithium silicate glass-ceramic. Dent Mater 2016;32(7):908-14.

[5] Borba M, de Araujo MD, Fukushima KA, Yoshimura HN, Cesar PF, Griggs JA, et al. Effect of the microstructure on the lifetime of dental ceramics. Dent Mater 2011;27(7):710-21.

[6] Vita Suprinity ${ }^{\oplus}$. Technical and scientific documentation. Bad Säckingen, Germany: Vita Zahnfabrik; 2014.

[7] Celtra Duo ${ }^{\oplus}$. Celtra block for cerec and inlab. DeguDent $\mathrm{GmbH}$, Hanau, Wolfgang, Alemanha: Dentsply Indústria e Comércio Ltda; 2014

[8] Traini T, Sinjari B, Pascetta R, Serafini N, Perfetti G, Trisi P, et al. The zirconia-reinforced lithium silicate ceramic: lights and shadows of a new material. Dent Mater J 2016;35(5):748-55.

[9] Ramos NC, Campos TM, Paz IS, Machado JP, Bottino MA, Cesar PF, et al. Microstructure characterization and SCG of newly engineered dental ceramics. Dent Mater 2016;32(7):870-8.

[10] Sato TP, Anami LC, Melo RM, Valandro LF, Bottino MA. Effects of surface treatments on the bond strength between resin cement and a new zirconia-reinforced lithium silicate ceramic. Oper Dent 2016;41(3):284-92.

[11] D'Arcangelo C, Vanini L, Rondoni GD, De Angelis F. Wear properties of dental ceramics and porcelains compared with human enamel. J Prosthet Dent 2016;115(3):350-5.
[12] ISO-6872. International Organization for Standardization, ISO/CD 6872. Dentistry ceramic materials; 2008 https://www.iso.org/standard/41385.html.

[13] Pereira G, Amaral M, Cesar PF, Bottino MC, Kleverlaan CJ, Valandro LF. Effect of low-temperature aging on the mechanical behavior of ground Y-TZP. J Mech Behav Biomed Mater 2015;45:183-92

[14] Quinn JB, Quinn GD. A practical and systematic review of Weibull statistics for reporting strengths of dental materials Dent Mater 2010;26(2):135-47.

[15] ASTM C1327-15. Standard test method for Vickers indentation hardness of advanced ceramics. West Conshohocken, PA: American Society for Testing and Materials; 2015, http://dx.doi.org/10.1520/C1327-15 https://www.astm.org/Standards/C1327.htm.

[16] ASTM E384-89. Standard test method for microhardness of materials. Philadephia: American Society for Testing and Materials; 1997 https://www.astm.org/Standards/E384.

[17] ISO-15732. International Organization for Standardization. Fine ceramics (advanced ceramics, advanced technical ceramics) - test method for fracture toughness of monolithic ceramics at room temperature by single edge precracked beam (SEPB) method; 2003. Geneva; https://www.iso.org/standard/28366.html.

[18] JIS-R 1607. Japanese Standards Association. Testing methods for fracture toughness of fine ceramics at room temperature; 2010.

[19] Shimadzu Micro Hardness Tester HMV-G21. Instruction manual. Japan: Shimadzu Corporation; 2012.

[20] Lawson NC, Bansal R, Burgess JO. Wear, strength, modulus and hardness of CAD/CAM restorative materials. Dent Mater 2016;32(11):e275-83.

[21] Krüger S, Deubener J, Ritzberger C, Höland W. Nucleation kinetics of lithium metasilicate in $\mathrm{ZrO}_{2}$-bearing lithium disilicate glasses for dental application. Int J Appl Glass Sci 2013;4:9-19.

[22] Aurélio IL, Dorneles LS, May LG. Extended glaze firing on ceramics for hard machining: crack healing, residual stresses, optical and microstructural aspects. Dent Mater 2017;33(2):226-40.

[23] Schwindling FS, Rues S, Schmitter M. Fracture resistance of glazed, full-contour ZLS incisor crowns. J Prosthodont Res 2017;61(3):344-9.

[24] Marshall DB, Cook RF, Padture NP, Oyen ML, Pajares A, Bradby JE, et al. The compelling case for indentation as a functional exploratory and characterization tool. J Am Ceram Soc 2015;98(9):2671-80.

[25] Fett T, Kounga N, Njiwa ABR. Crack opening displacements of Vickers indentation cracks. Eng Fract Mech 2005;72(5):647-59. 